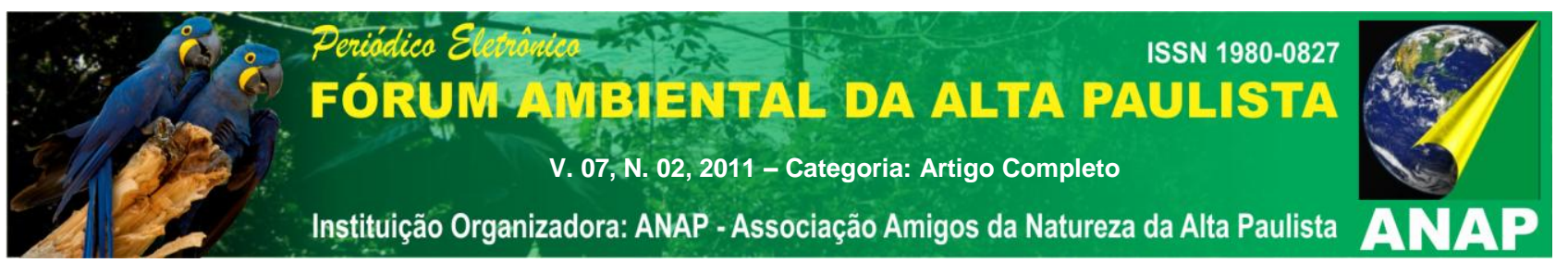

\title{
GEOTECNOLOGIAS APLICADAS PARA FINS DE PLANEJAMENTO AMBIENTAL: ANÁLISE MULTITEMPORAL DA BACIA HIDROGRÁFICA DO RIBEIRÃO BRIOSO - MS BRASIL
}

\author{
Eduardo Vinícius Rocha Pires ${ }^{1}$ \\ Renan de Almeida Silva ${ }^{2}$ \\ Flavia Joise Izippato ${ }^{3}$ \\ Patrícia Helena Mirandola ${ }^{4}$
}

Resumo: Este trabalho tem como objetivo elaborar e analisar o mapeamento de uso e ocupação da terra da Bacia Hidrográfica do Ribeirão Brioso (BHRB). A BHRB está localizada na porção leste do Estado de Mato Grosso do Sul inserida totalmente no município de Três Lagoas/MS. Para este trabalho foram utilizados cartas topográficas, imagem orbital do sensor remoto Thematic Mapper (TM), Imagens de Radar da Missão SRTM, Hardware e Software Spring. Os procedimentos operacionais utilizados basearam-se na aquisição, armazenamento, manipulação, análise e apresentação de dados georreferenciados. Com a imagem orbital Landsat TM, elaborou-se o mapeamento de uso e ocupação da terra utilizando a classificação supervisionada predominou-se, respectivamente a classe pastagem, eucalipto, mata, e água. Em relação ao método utilizado ficou evidente sua eficácia, pois a aquisição, manipulação e armazenamentos dos dados da área de estudo foram processados e transformados em informações que podem subsidiar o planejamento da área de estudo (BHRB).

Palavras chave: Geoprocessamento, Bacia Hidrográfica e Planejamento.

\footnotetext{
${ }^{1}$ Graduando em geografia - UFMS/CPTL. Bolsista de iniciação científica PIBIC - CNPq e membro do DIGEAGEO (Diretrizes de Gestão Ambiental com Uso de Geotecnologias). Email: drocha.geo@gmail.com

${ }^{2}$ Graduando em geografia - UFMS/CPTL. Bolsista de iniciação científica PIBIC - CNPq e membro do DIGEAGEO (Diretrizes de Gestão Ambiental com Uso de Geotecnologias). Email: geo.renanalmeida@gmail.com

${ }^{3}$ Mestranda do Programa de Pós-graduação em Geografia UFMS/CPTL. Bolsista Capes e membro do DIGEAGEO (Diretrizes de Gestão Ambiental com Uso de Geotecnologias). Email: flaviajoise@gmail.com

4 Docente do Programa de Pós-graduação em Geografia - UFMS/CPTL. Líder do grupo DIGEAGEO (Diretrizes de Gestão Ambiental com Uso de Geotecnologias). Email: patriciaufmsgeografia@gmail.com
} 


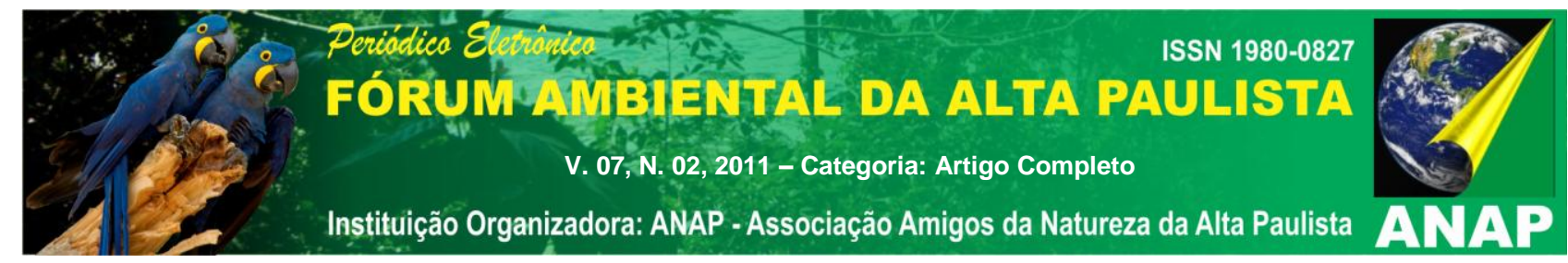

\section{INTRODUÇÃO}

O presente trabalho é uma parte componente de um projeto maior que estuda a Bacia Hidrográfica do Rio Sucuriu, financiado pelo CNPq, para poder atender aos objetivos propostos no projeto maior, este subprojeto, visa identificar, analisar, a situação atual da Bacia Hidrográfica do Ribeirão Brioso, que é um dos afluentes do Rio Sucuriu.

Esta pesquisa elaborou um mapeamento do uso e ocupação da terra na Bacia Hidrográfica do Ribeirão Brioso (BHRB) com uso de técnicas de Geoprocessamento e Sensoriamento remoto para fins de planejamento ambiental da área.

Planejamento Ambiental é o processo de organização do trabalho para consecução de objetivos comuns, de forma que os impactos resultantes que afetam negativamente 0 ambiente em que vivemos sejam minimizados e que os impactos positivos sejam maximizados.

O termo planejamento compreende vastas atividades, para Ab'sáber (1969, p. 11-12) planejamento significa elaborar planos de melhoria, encontrar diretrizes para corrigir os espaços improdutivos e impactados, além de encontrar meios e propiciar condições para interferir nos setores menos favoráveis de uma estrutura ou de uma conjuntura.

Assad e Sano (1993), salientaram que, para planejamento e gerenciamento sejam aplicados de forma eficaz é recomendado que se estabelecesse unidades básicas hidrográficas de planejamento, no que diz respeito aos parâmetros ambientais.

No território de Mato Grosso do Sul configuram-se duas das 12 Regiões Hidrográficas do Brasil, conforme definidas pela Resolução no 32/2003 do Conselho Nacional de Recursos Hídricos (CNRH, 2000): as Regiões Hidrográficas do Paraguai, constituída pela bacia do rio Paraguai, a oeste, e as Regiões Hidrográfica do Rio Paraná, constituída pela bacia do rio Paraná, a leste. (PERH-MS, 2009). 


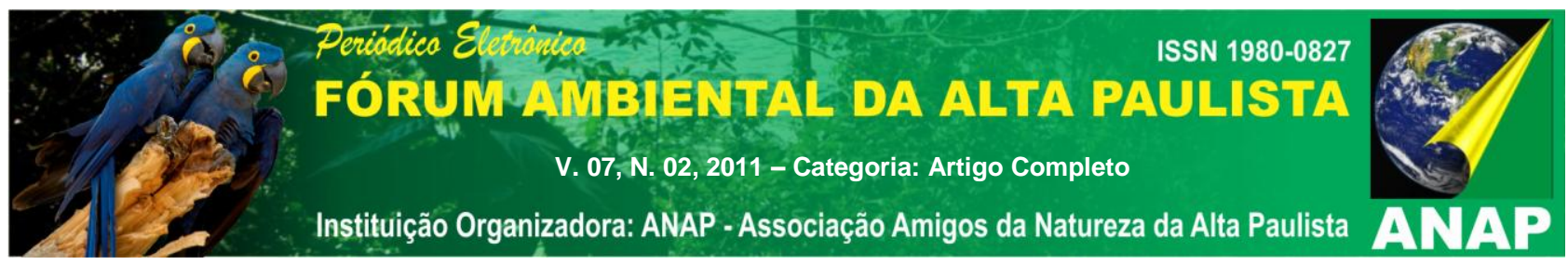

No intuito de realizar um estudo integrado do ambiente vêem na análise da Geografia Física uma maneira de se estudar o meio como um todo e Christofoletti (1999) é um dos expositores de como deve haver o estudo de ambientes.

Os sistemas ambientais físicos representam a organização espacial resultante da interação dos elementos componentes físicos da natureza (clima, topografia, rochas, águas, vegetação animais, solos) possuindo expressão espacial na superfície terrestre e representando uma organização composta por elementos, funcionando através dos fluxos de energia e matéria, dominante numa interação areal (CHRISTOFOLETTI, 1999, p. 42).

Segundo Bertalanffy (1972), existe uma relação entre todos os elementos e constituintes da sociedade. Os fatores essenciais dos problemas públicos, das questões e programas a adotar devem sempre ser considerados e avaliados como componentes interdependentes de um sistema total.

De acordo com Mendonça (1997) apud Ferreira (2010), a identificação da ocupação e uso da terra constitui-se em importante elemento para um estudo ligado à temática ambiental, pois o dado mais atualizado sobre uma determinada área auxiliará, dentre outros, na identificação e localização dos agentes responsáveis pelas suas condições ambientais. 


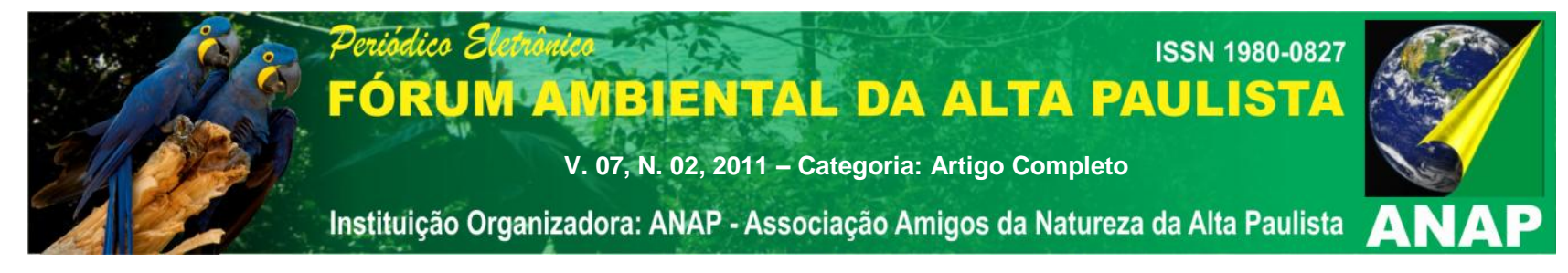

\section{LOCALIZAÇÃO SISTEMICA DA BHRB}
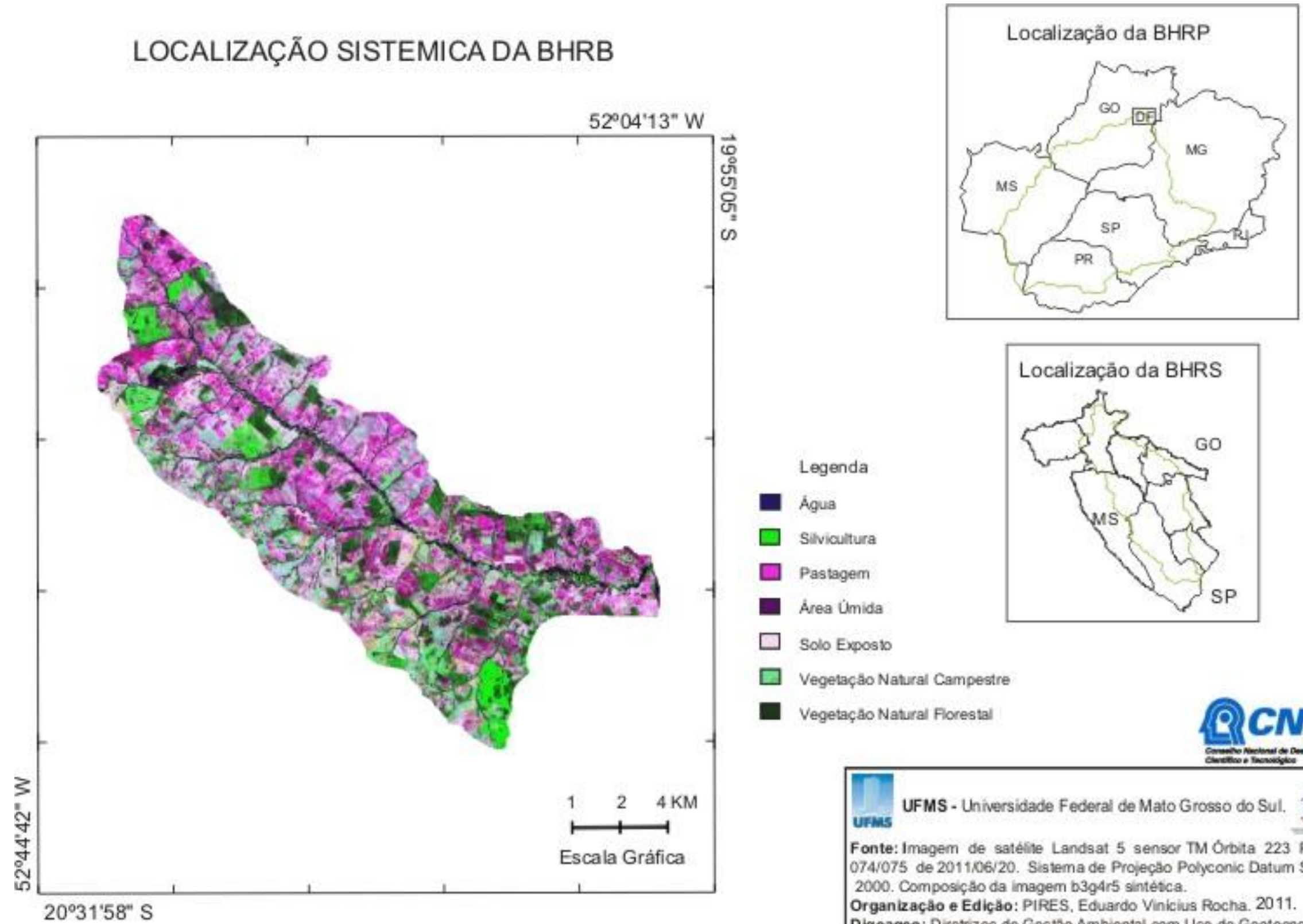

$\square$ Vegetaçăa Natural Campestre

- Vegetaça Natural Forestal

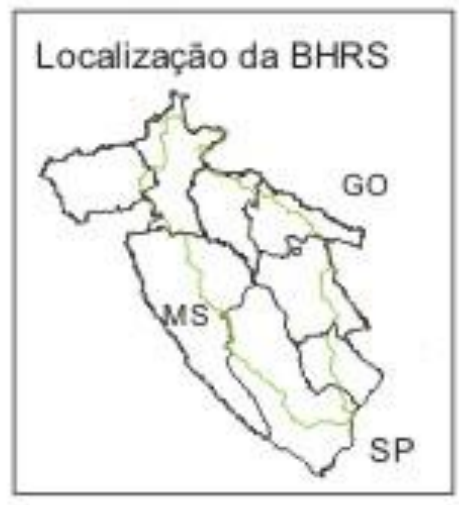

Fonte: Imagem de satélite Landsat 5 sensor TM Óbita 223 Ponto 074/075 de 2011/06/20. Sistema de Projeçáo Polyconic Datum Sirgas 2000. Composiçăo da imagem b3g4r5 sintetica.

Organizaçăo e Ediçăo: PIRES, Eduardo Vinicius Rocha. 2011.

Digeageo: Diretrizes de Gestao Ambiental com Uso de Geotecnologias. 


\section{LOCALIZAÇÃO DA ÁREA DE ESTUDO}

A área de estudo deste trabalho, a Bacia Hidrográfica do Ribeirão Brioso (BHRB) - MS está localizada na porção leste do Estado de Mato Grosso do Sul inserida totalmente no município de Três Lagoas /MS entre as coordenadas geográficas 5244'42" a 5204'13" W e 2031'58" a 1955'05" S e abrange uma área de aproximadamente 10.213,6 km². O Ribeirão Brioso é afluente da margem direita do Rio Sucuriú, que é afluente da margem direita do Rio Paraná.

Tendo em vista a abordagem sistêmica que fora tomada, a BHRB faz parte de um sistema maior, no qual se denomeia de Bacia Hidrográfica do Rio Paraná, que tem Omo afluente a Bacia Hidrográfica do Rio Sucuriú, subsistema onde se deságua a parte componente Bacia Hidrográfica do Ribeirão Brioso.

Tendo como apoio a Teoria Geral dos Sistemas a presente análise está estruturada da seguinte forma:

- Bacia Hidrográfica do Rio Paraná - Sistema

- Bacia Hidrográfica do Rio Sucuriú - Subsistema

- Bacia Hidrográfica do Ribeirão Brioso - Partes Componentes

\section{MATERIAIS E PROCEDIMENTOS OPERACIONAIS}

Para este trabalho foram utilizadas imagens orbitais do sensor remoto Thematic Mapper (TM) órbita 223, ponto 074, dos anos de 1985 e 2011, Hardware e Software SPRING® desenvolvido pelo Instituto de Pesquisas Espaciais (INPE), CorelDRAW® 12 e Microsoft Excel 2007.

Os procedimentos operacionais utilizados basearam-se na aquisição, armazenamento, manipulação, análise e apresentação de dados georreferenciados e processados em ambiente de Sistema Geográfico. 


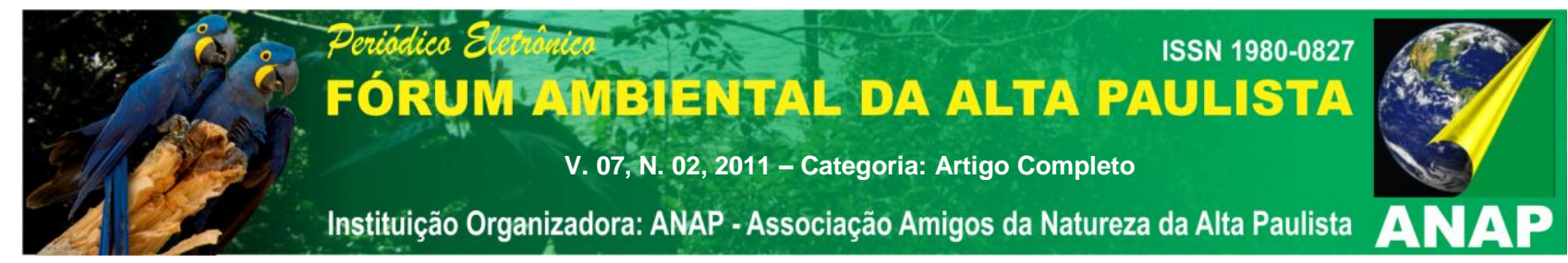

A primeira etapa dos procedimentos operacionais baseou-se na criação de um banco de dados e posteriormente na elaboração do projeto com a delimitação do retângulo envolvente da área de estudo. A segunda etapa elaborou-se o georreferenciamento(registro) das cenas Landsat TM e posteriormente foram aplicados procedimentos de processamento nas imagens TM como: elaboração de contraste, segmentação e classificação por região, utilizando o classificador Battacharya com um liminar de aceitação de 99,9\% e similaridade de 10 e área 8 pixel.

Em seguida criaram-se categorias com as classes temáticas: Silvicultura, Pastagem, Vegetação Natural Florestal, Vegetação Natural Campestre, Vegetação Úmida, Área Urbanizada, Água Continental, Solo Exposto. Por fim, quantificou-se e analisaram-se as classes temáticas do mapa de uso e ocupação da terra da Bacia Hidrográfica do Ribeirão Brioso.

Para a confecção mapa de uso e ocupação da terra, utilizou-se o método proposto pelo IBGE no Manual do Uso da Terra. O manual apresenta o desenho esquemático dos fluxos existentes no processo de levantamento e classificação da Cobertura e do Uso da Terra além de propor cores na legenda do mapa de uso e ocupação da terra da BHRB (Quadro 1).

\begin{tabular}{|c|c|c|}
\hline Nivel I & & Nivel II \\
\hline \multirow{2}{*}{$\begin{array}{l}\text { 1- Areas Antropicas } \\
\text { NÁ Agricolas }\end{array}$} & 1.1 & Area Urbancaada \\
\hline & 12 & Aurea de Nineracalo \\
\hline \multirow{4}{*}{$\begin{array}{l}\text { 2. Area Antropicars } \\
\text { Agrioolas }\end{array}$} & 2.1 & Cultura Temporairia \\
\hline & 2.2 & Cultura Permanente \\
\hline & 2.3 & Pastagem \\
\hline & 2.4 & Silvicultura \\
\hline \multirow{2}{*}{$\begin{array}{l}\text { 3. Areas de } \\
\text { Vegetacalo Natural }\end{array}$} & 3.1 & Florestal \\
\hline & 3.2 & Campestre \\
\hline \multirow{2}{*}{ 4. Agua } & 4.1 & Corpos dragua continentais \\
\hline & 4.2 & Corpos dragua costeiros: \\
\hline
\end{tabular}




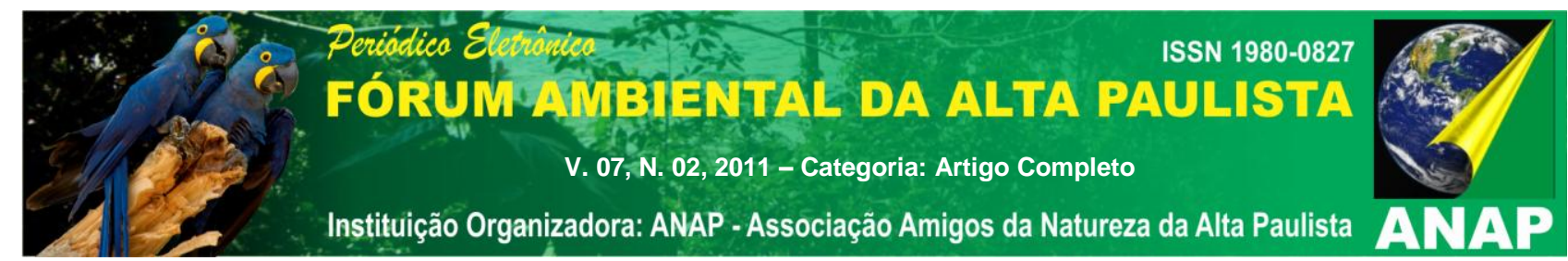

Quadro 1: Cores e classes do Uso e Ocupação da Terra Fonte: IBGE (2006)

Quanto à classe vegetação úmida (mata ciliar), não consta na tabela do IBGE, esta classe foi inserida por constar no mapa na primeira analise, sendo usada por trabalhos da mesma disciplina.

\section{RESULTADOS}

Os cenários de ambientes construídos ou transformados pela ação do homem ocupam a maior parte dos sistemas ambientais. O homem transforma os espaços através da derrubadas de matas, da implantação de pastagens e cultivos, da construção de estradas, portos aeroportos, represas, da retificação e canalização de curso d'água, da implantação de indústrias e áreas urbanas. (FLORENZANO, 2002 apud MIRANDOLA-AVELINO, 2006).

Assim as imagens de satélite da área da bacia hidrográfica do Ribeirão Brioso permitem a visualização geral do ambiente nos anos de 1985 e2011, proporcionando uma visão atual, que possibilita uma comparação dessas e uma ação planejada para o futuro do ambiente estudado. As quantificações que serão apresentadas estarão associadas às imagens de satélite, que nos permitirá avaliar os processos e formas da interação sociedade natureza na organização da área da parte componente, contribuindo assim a subsidiar a tomada de decisão no planejamento ambiental da bacia hidrográfica do Ribeirão Brioso.

$\mathrm{Na}$ classe temática vegetação natural florestal considerou-se áreas florestais, áreas de reserva legal e matas ciliares. Obteve-se também no mapeamento da classe pastagem, caracterizada pela presença de gramíneas destinadas a nutrição animal e a classe vegetação natural campestre, onde também é utilizada pelos pecuaristas como local de criação bovina. 


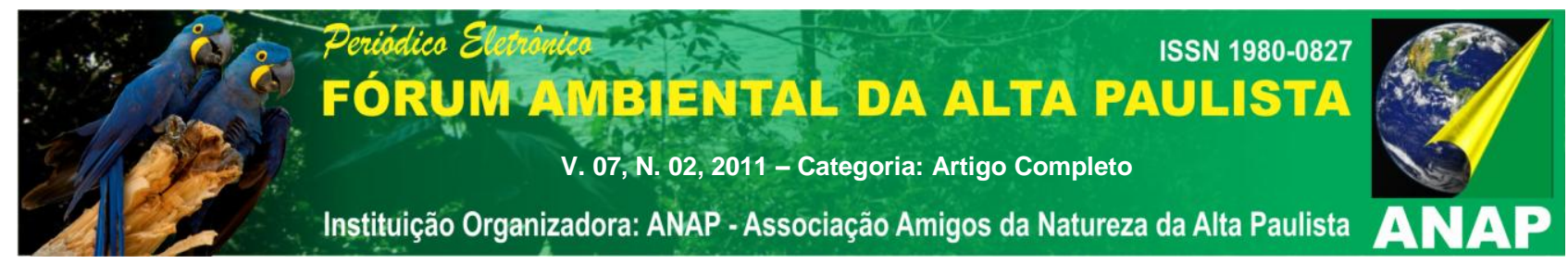

No ano de 1985 predominou-se a classe temática Pastagem e Vegetação Campestre, já que os mesmos são tradicionalmente usados como área de pecuária, acompanhando a paisagem do Estado do Mato Grosso do Sul, já que o mesmo é o maior produtor de gados do Brasil. A classe Vegetação Úmida ainda possuía 12,13\% da área total, já que a Vegetação Natural Florestal ainda não era muito explorada. A área utilizada para a prática da Silvicultura ainda era e $37,9 \mathrm{~km}^{2}$, aproximadamente $0,4 \%$ da área total da BHRB, como mostra o Gráfico1.

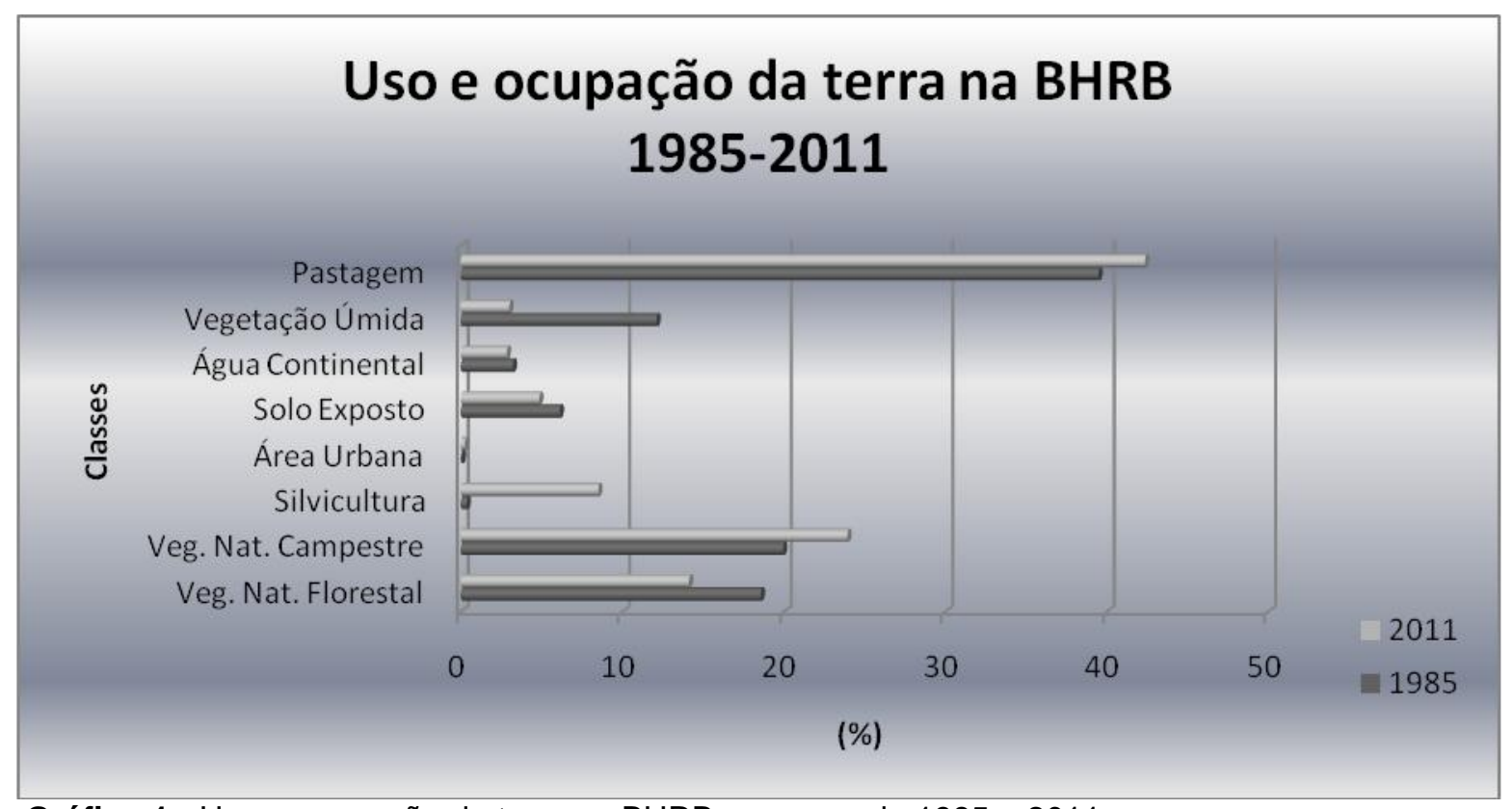

Gráfico 1.: Uso e ocupação da terra na BHRB nos anos de 1985 e 2011.

Fonte: Processamento Digital de Imagem de Satélite Landsat5 sensor TM- 1985/30/07 e 2011/20/06 Organização: PIRES, E. V. R.

Posteriormente, outro ano analisado com o uso das geotecnologias foi 2011. Os estudos apontaram as mesmas seis classes principais do uso e ocupação da terra, a única diferença foram os valores percentuais de cada classe.

Em um primeiro momento, observamos que algumas áreas aumentaram enquanto algumas diminuíram, ou seja, o espaço do município não se encontra da mesma forma, posteriormente havendo uma dinâmica de mudança. 


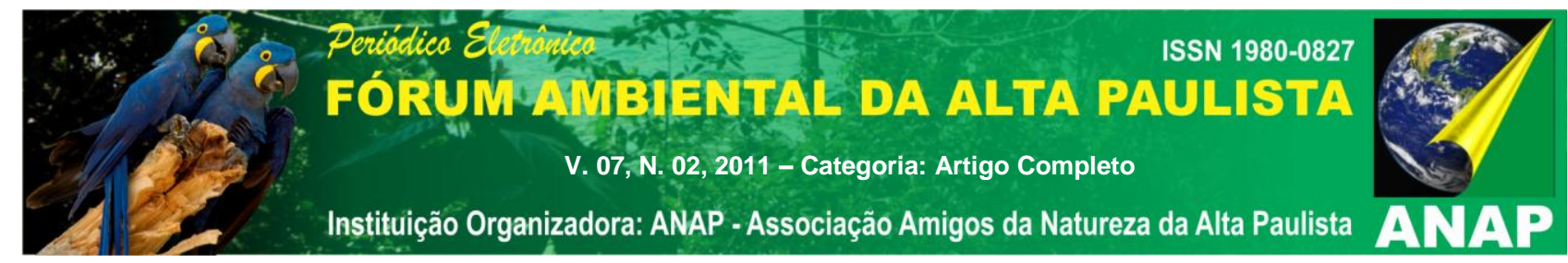

A classe vegetação úmida, por exemplo, que em 1985 se encontrava com aproximadamente 12,13\% (1239 $\left.\mathrm{Km}^{2}\right)$, em 2011 teve uma diminuição de aproximadamente $25 \%$ ficando com uma área aproximada de $307,6 \mathrm{Km}^{2}$.

Com a análise de gabinete das imagens de satélite, pudemos observar que em 2011 , houve um grande avanço da vegetação natural campestre e da Pastagem nesse local, levando em consideração a resolução do satélite que é de $30 \mathrm{~m}^{2}$ e a data em que o Lansat5 TM obteve a imagem.

Em classe temática Vegetação Natural Florestal (áreas florestais, áreas de reserva legal e matas ciliares), percebe-se uma diminuição de aproximadamente $24 \%$ nesses vinte e seis anos, consequentemente diminuindo a Vegetação Úmida da BHRB. Assim, percebe-se a diminuição das reservas legais e o comprimento das leis ambientais nesses devidos locais, conforme os dados do Quadro 2. e da Figura 1, que mostra nos mapas essa dinâmica das classes temáticas.

\begin{tabular}{|c|c|c|c|c|}
\hline \multirow{2}{*}{ CLASSES } & \multicolumn{2}{|c|}{1985} & \multicolumn{2}{c|}{2011} \\
\cline { 2 - 5 } & Área $\left(\mathrm{km}^{2}\right)$ & Porcentagem(\%) & Área(km²) & Porcentagem(\%) \\
\hline $\begin{array}{c}\text { Vegetação Natural } \\
\text { Florestal }\end{array}$ & 1898,78 & 18,59 & 1444,53 & 14,14 \\
\hline $\begin{array}{c}\text { Vegetação Natural } \\
\text { Campestre }\end{array}$ & 2039,19 & 19,96 & 2445,9 & 23,95 \\
\hline Silvicultura & 37,87 & 0,37 & 870,26 & 8,52 \\
\hline Área Urbana & 6,89 & 0,07 & 26,25 & 0,26 \\
\hline Solo Exposto & 627,67 & 6,14 & 497,68 & 4,87 \\
\hline Água Continental & 330,07 & 3,23 & 292,23 & 2,86 \\
\hline Área Úmida & 1238,98 & 12,13 & 307,62 & 3,01 \\
\hline Pastagem & 4034,73 & 39,5 & 4328,64 & 42,38 \\
\hline Total & 10214,18 & 100 & 10213,11 & 100 \\
\hline
\end{tabular}

Quadro 2: Comparação das classes Temáticas utilizadas na pesquisa dos anos de 1985 e2011 Fonte: Digital de Imagem de Satélite Landsat5 sensor TM- 1985/30/07 e 2011/20/06

Organização: PIRES, E. V. R. 


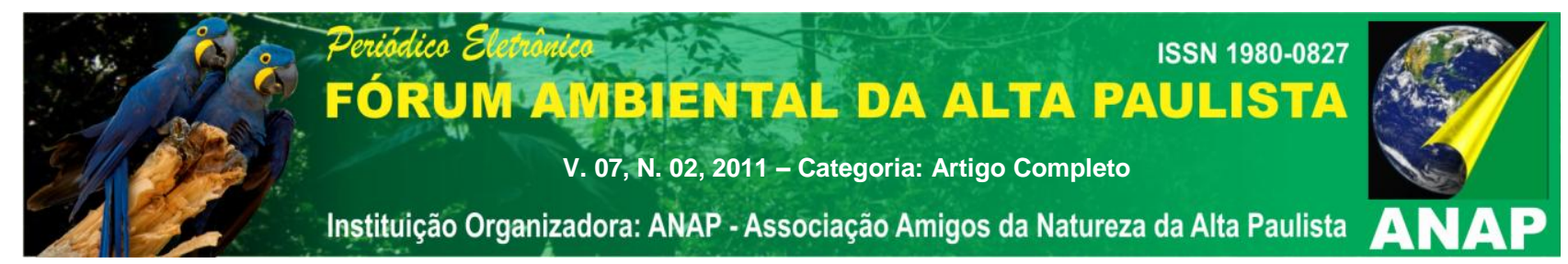




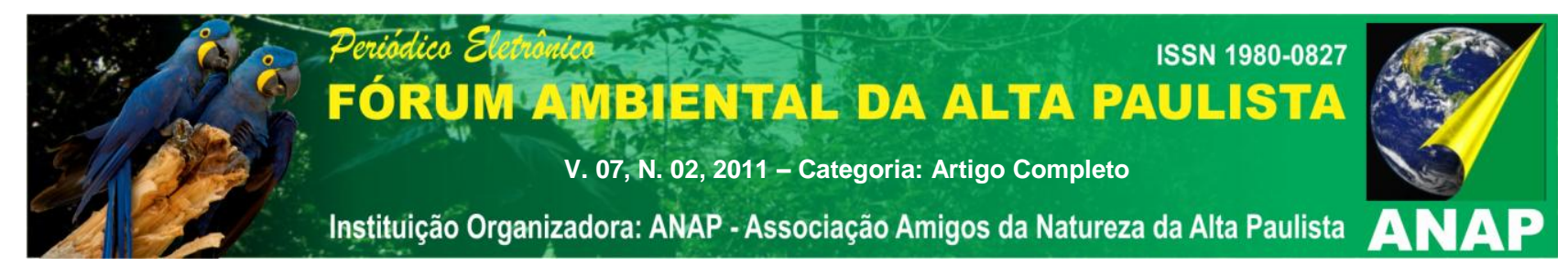

MAPA DE USO E COBERTURA DA TERRA DA BACIA HIDROGRÁFICA DO RIBEIRÃO BRIOSO/MS.
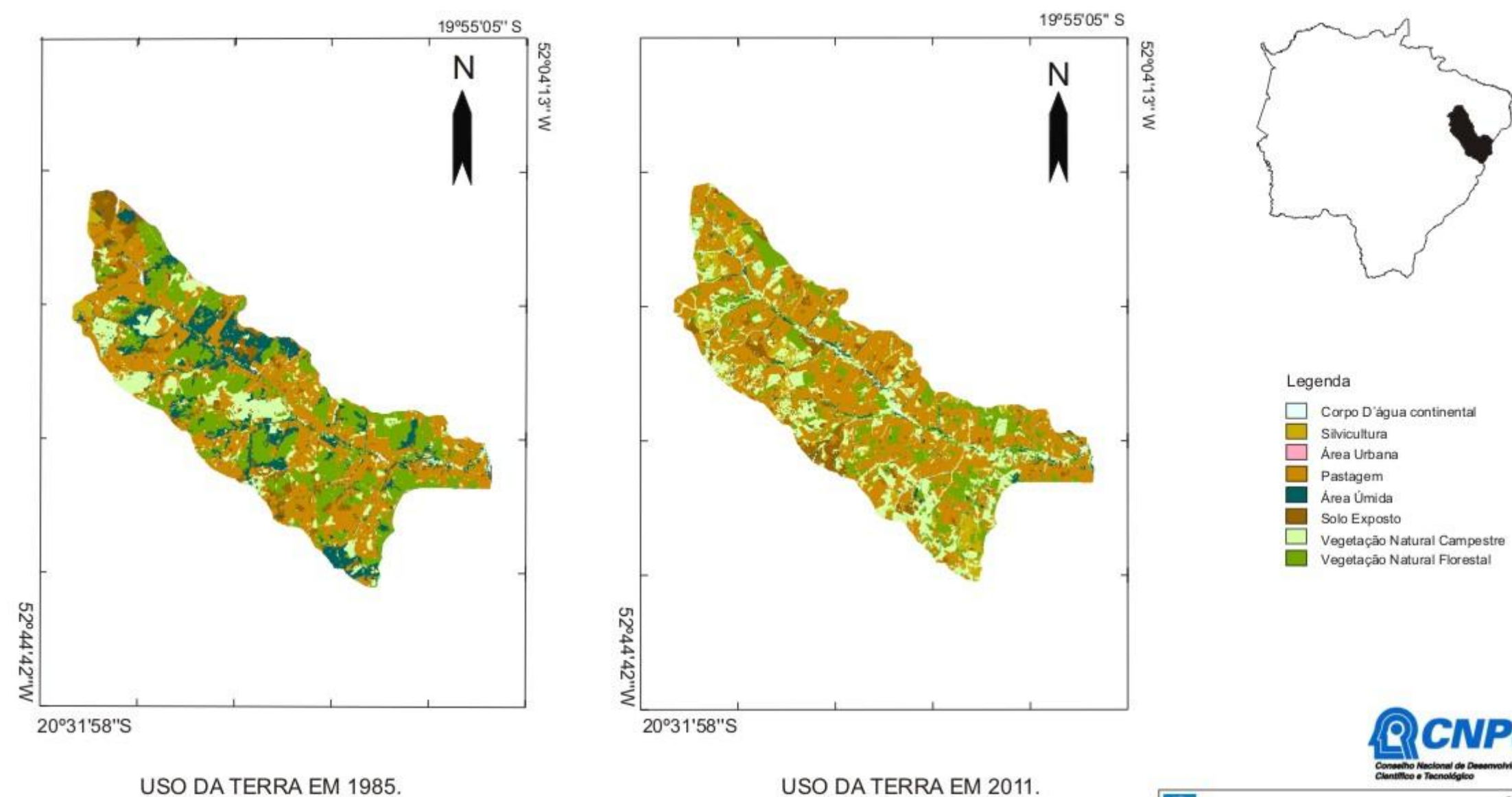

USO DA TERRA EM 1985.

USO DA TERRA EM 2011.

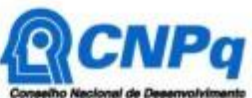
Manc Grosso do Su. की

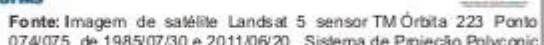

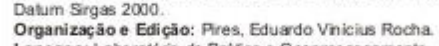




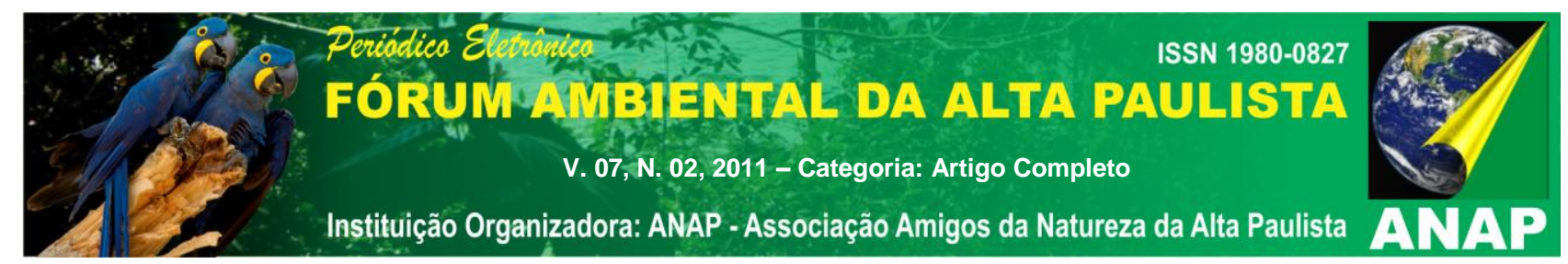

Figura 3: Mapa de Uso e Ocupação da terra da Bacia Hidrográfica do Ribeirão Brioso. 


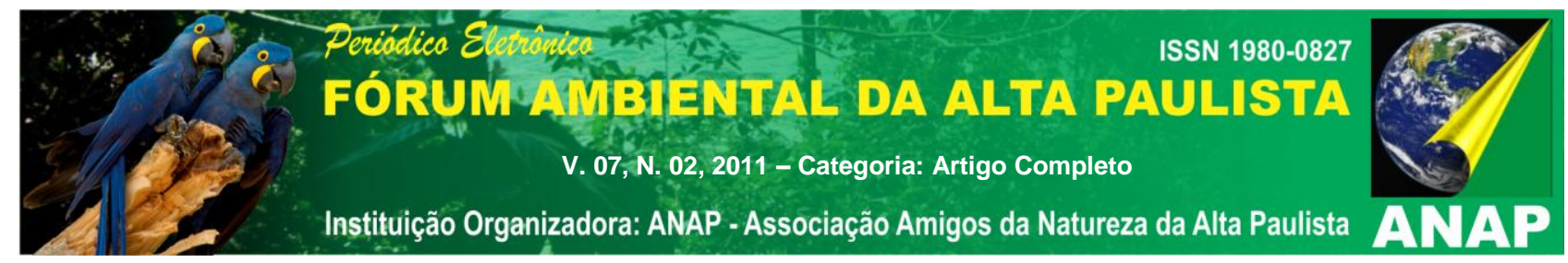

\section{Considerações Finais}

Em relação ao método e procedimentos utilizados, ficou evidente sua eficácia, pois, a aquisição, manipulação e armazenamentos dos dados da área de estudo foram processados e transformados em informações que podem subsidiar o planejamento da área. $O$ mapa gerado com as áreas das classes temáticas permitiu quantificar e avaliar a situação atual do uso e ocupação da terra da BHRB no âmbito geográfico.

O uso conjugado das geotecnologias é elemento essencial para determinar o tipo de uso e ocupação da terra em toda extensão da Bacia Hidrográfica do Ribeirão Brioso - MS, pois a aquisição, manipulação e armazenamentos dos dados da área de estudo foram processados e transformados em informações que podem subsidiar o planejamento da área.

\section{Bibliografia}

AB'SÁBER, Aziz, Nacib. Geografia e planejamento. In: 2 geografia e planejamento. Instituto de geografia da Universidade de São Paulo. Edanee: São Paulo, 1969.

ASSAD, E. D.; SANO, E. E. Sistemas de Informação Geográficas: Aplicações na Agricultura. Platina: Embrapa, 1993.

CÂMARA, G.; SOUZA, R. D. M.; FREITAS, U. M.; GARRIDO, J. \& MITSUO, F. Spring: integrating Remote Sensing and GIS by object - Oriented Data Modelling. São Jose dos Campos, 1996, 17p. Disponível em:

http://citeseerx.ist.psu.edu/viewdoc/download?doi=10.1.21.3610\&rep=rep1\&tyte=pdf. Acesso em 12/05/2011.

CHRISTOFOLETTI, A. Geomorfologia. São Paulo: Edgard Blücher, 2. ed., 1980. 


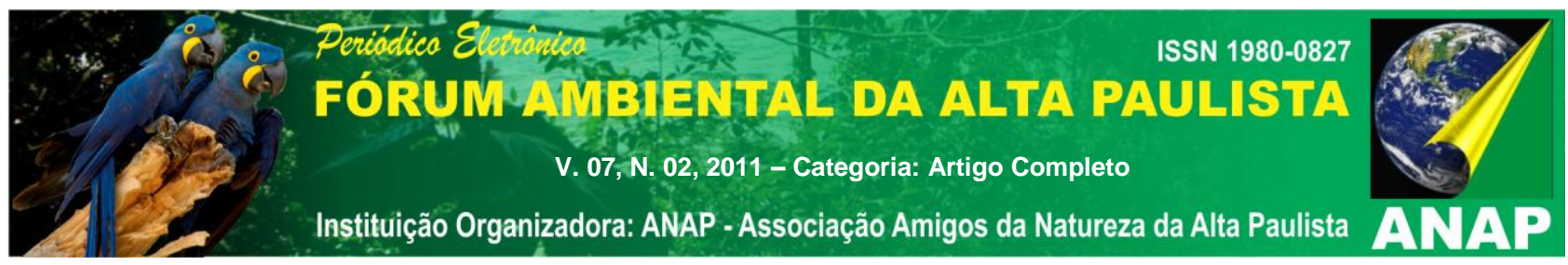

CHRISTOFOLETTI, A. Modelagem de sistemas ambientais. $1^{\circ}$ ed. São Paulo: Edgar Blücher, 1999.

FERREIRA, C.C. Uso de imagens de sensoriamento remoto para mapeamento do uso e ocupação da terra da Bacia Hidrográfica do Alto Sucuriú- MS-BR. II Simpósio Internacional da Cartografia na Geografia. São Paulo. 2010.

IBGE. Manual Técnico do Uso da Terra. Ed. 2, n. 7. Rio de Janeiro, 2006.

INPE.(Instituto Nacional de Pesquisas Espaciais). Imagem LANDSAT TM, Órbita 223, ponto 074 - 30/07/1985. Departamento de Geração de Imagens.

INPE.(Instituto Nacional de Pesquisas Espaciais). Imagem LANDSAT TM, Órbita 223, ponto 074 - 20/06/2011. Departamento de Geração de Imagens.

MIRANDOLA-AVELINO, Patricia. Helena. Análise geo - ambiental multitemporal para fins de planejamento ambiental: um exemplo aplicado à bacia hidrográfica do Rio Cabaçal Mato Grosso - Brasil. Tese de Doutorado em Geografia do Programa de Pós Graduação em Geografia da Universidade Federal do Rio de Janeiro, 2006, 317 p.

PLANO ESTADUAL DE RECURSOS HÍDRICOS DE MATO GROSSO DO SUL. Governo do Estado de Mato Grosso do Sul - SEMAC e IMASUL, 2009. 